\title{
A Comparative Analysis for a Novel Irrigation Method: Partial Rootzone Drying
}

\author{
Alaa Abdallah El-Sadek1, Mona Ezo Radwan², Ahmed Ali Salih ${ }^{1}$ \\ ${ }^{1}$ Arabian Gulf University, Manama, Kingdom of Bahrain \\ ${ }^{2}$ Nile Research Institute, National Water Research Center, El Qanater El Khairia, Egypt \\ Email: alaa_elsadek@yahoo.com,mona_radwan2@yahoo.com
}

How to cite this paper: El-Sadek, A.A., Radwan, M.E. and Salih, A.A. (2018) A Comparative Analysis for a Novel Irrigation Method: Partial Rootzone Drying. Journal of Agricultural Chemistry and Environment, 7, 34-44.

https://doi.org/10.4236/jacen.2018.71004

Received: December 5, 2017

Accepted: February 3, 2018

Published: February 6, 2018

Copyright () 2018 by authors and Scientific Research Publishing Inc. This work is licensed under the Creative Commons Attribution International License (CC BY 4.0).

http://creativecommons.org/licenses/by/4.0/

\begin{abstract}
Partial Rootzone Drying (PRD) is an irrigation technique which offers a means of modifying the growth and development of crops through relatively simple changes to the method of water delivery. The technique causes the stimulation of physiological responses which are normally associated with water stress and this results in a significant reduction in water use through the production of chemical signals in drying roots. Partial drying of one half of the roots of plants grown with two root systems is rapidly translated into a reduction in transpiration and assimilation of all the crop leaves. The aim of this research is to examine and simulate the novel irrigation method (PRD), which would stimulate the endogenous stress response mechanisms of Conocarpus erectus trees in the pilot area of the Arabian Gulf University in Bahrain and wheat and maize crops in the Mashtul Pilot Area (MPA), Egypt using Saltmed model so that vigor is reduced and the efficiency of water use is enhanced. This is to be achieved by the manipulation of the hydration status of parts of a crop's roots that could be used to control vegetative vigor without detrimental effects on canopy water relations. The PRD technique is researched for wheat as a winter crop and maize as a summer crop in Egypt. The technique causes the stimulation of physiological responses which are normally associated with water stress and this results in a significant reduction in water use through the production of chemical signals in drying roots. The results confirmed an increase in irrigation water use efficiency using PRD comparing with conventional flood irrigation. The research highly recommends applying the PRD method in the Gulf Cooperation Council (GCC) countries and in new reclaimed areas in Egypt to save water and improve crop quality.
\end{abstract}

\section{Keywords}

Partial Rootzone Drying, Conocarpus Erectus Trees, MPA, GCC 


\section{Introduction}

Irrigation requirements are sometimes estimated from environmental data (pan evaporation, soil moisture reserves and rainfall) and crop factors. Crop factors are multipliers which reflect the water requirement of a particular crop at different times of the year and depend on variables such as canopy area and stage of growth. They can vary by a factor of five and the success of this method of determining irrigation input is very much dependent on the use of realistic crop factors. In determining these factors, little thought is given to internal physiological changes in the plants which may substantially influence their efficiency of water use in the short term. For example, it has been known for a long time that water deficits will induce changes in the gas exchange characteristics of a plant which results in reduced water loss. Such a decrease in water use would obviously be an advantage if it could be achieved without detriment to the crop or any other aspects of crop performance [1]. However, to get the plant to exhibit these changed characteristics, it would normally be necessary to induce a degree of water deficit. This may be difficult to achieve in a controlled way and furthermore, the plant will recover over a period of time, making repeat water deficit events necessary for a sustained effect. This may be possible, but difficult to achieve in practice, and it is known that sustained water deficits usually result in a reduction in fruit yield. Ideally it would be desirable to separate the positive effects of water deficits (improved water use efficiency and reduced allocation of resources to vegetative growth in comparison to fruit growth) from the negative effects such as reduced crop yield.

$\mathrm{PRD}$, as the name suggests, is the creation of simultaneous wet and dry (or drying) areas within the root zone. Only part of the root zone is irrigated and kept moist at any one time. PRD is implemented by irrigating one side of the plant row and allowing the other side to dry out. The irrigations are then alternated to the dry side after a set period of time and then back and forth thereafter the same period of time. If only part of the root system dried and the remaining roots were kept well watered, chemical signals produced in the drying roots reduced stomatal aperture. At the same time, the fully hydrated roots maintained a favorable water status throughout the aerial parts of the plant. In other words, it was possible to separate the biochemical responses to water stress from the physical effects of reduced water availability. In addition to reduced stomatal conductance, it is noted that shoot extension is also inhibited. A surprising finding is that the effect is temporary, and despite the fact that part of the root system remained dry, stomatal conductance, photosynthesis and growth returned to pre-treatment levels within a few weeks [2] [3]. The aim of this research is to examine and simulate the novel irrigation method (Partial Rootzone Drying, PRD), which would stimulate the endogenous stress response mechanisms of Conocarpus erectus trees in the pilot area of the Arabian Gulf University in Bahrain and wheat and maize crops in the Mashtul Pilot Area (MPA), Egypt using Saltmed model so that vigor is reduced and the efficiency of water use is 
enhanced [4]. This is to be achieved by the manipulation of the hydration status of parts of a crop's roots could be used to control vegetative vigor without detrimental effects on canopy water relations. In this paper, the PRD technique is researched for wheat as a winter crop and maize as a summer crop in Egypt. The technique causes the stimulation of physiological responses which are normally associated with water stress and this results in a significant reduction in water use through the production of chemical signals in drying roots. In addition, the research provides low cost irrigation techniques at farmers' level, monitors performance of the new techniques, and assesses the feasibility of implementation and the possibility of extrapolation.

\section{Case Studies}

\subsection{Experimental Pilot Area, Arabian Gulf University, Bahrain}

In the arid region countries where water resources are scarce and where agriculture sector consumes more than $80 \%$ of the total water resources, improving water use efficiencies would be the key to ensure food security in the region. Most of the area of the GCC countries is situated in an extremely arid zone. Groundwater is a vital and essential source for all water use sectors, where groundwater dependency ratio in the GCC countries averages about $75 \%$. At present, groundwater in the GCC countries are used extensively for irrigation purposes, experiencing over-exploitation and quality deterioration. Water scarcity is a key constrain facing the GCC agricultural sector which consumes more than $80 \%$ of the total water resources. In the face of rapid population growth and economic expansion, food security is presenting itself as an increasingly pressing policy concern in the GCC. Arid conditions in the GCC countries act as a natural constraint for expansive agriculture. Efforts to maintain a balance between scarce water and land resources and pursue domestic agriculture have prompted the introduction of modern water-saving irrigation techniques.

This study aimed to stimulate the endogenous stress response mechanisms of the plant so that vigor is reduced and the efficiency of water use is enhanced. The field was cultivated by Conocarpus erectus trees and data were collected. Only part of the root zone was irrigated and kept moist at any one time. PRD was implemented by irrigating one side of the tree row and allowing the other side to dry out. The irrigations were then alternated to the dry side after a set period of time and then back and forth thereafter the same period of time. This was achieved by the manipulation of the hydration status of parts of tree's roots which used to control vegetative vigor without detrimental effects on canopy water relations. If only part of the root system dried and the remaining roots were kept well watered, chemical signals produced in the drying roots reduced stomatal aperture. At the same time the fully hydrated roots maintained a favorable water status throughout the aerial parts of the tree. In addition to reduced stomatal conductance, it was noted that shoot extension is also inhibited. A surprising finding was that the effect is temporary, and despite the fact that 
part of the root system remained dry, stomatal conductance, photosynthesis and growth returned to pre-treatment levels within five weeks. The growing stages of the Conocarpus erectus trees are shown in Figure 1.

(October 1, 2014)
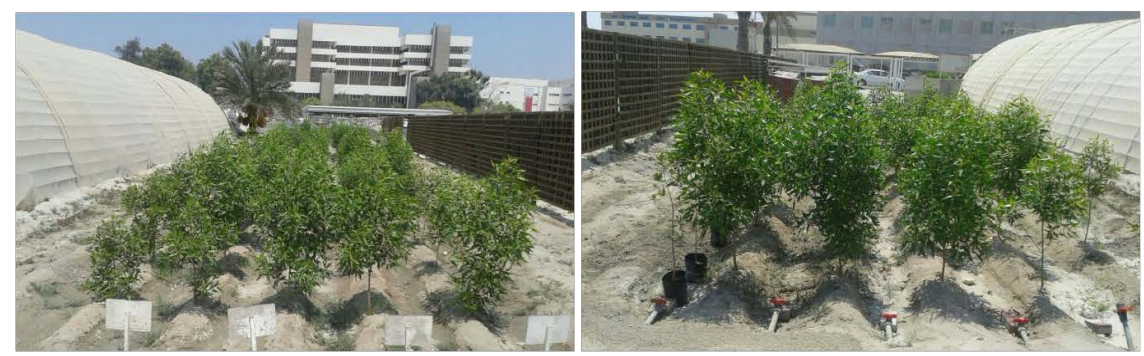

(November 1, 2014)
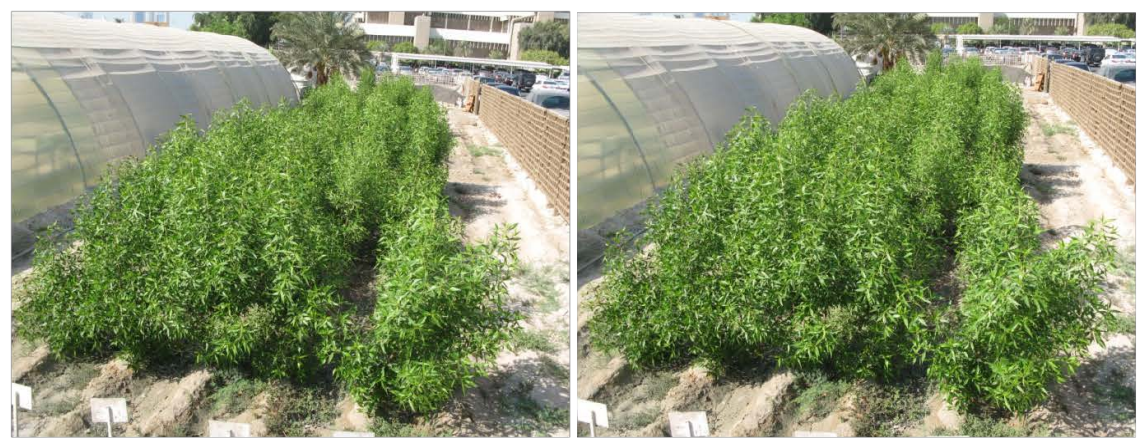

(December 1, 2014)

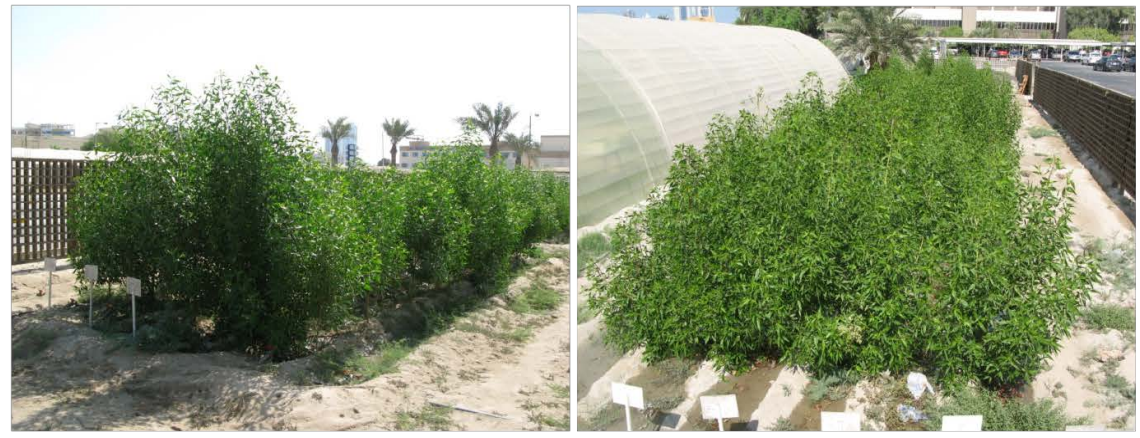

(January 1, 2015)
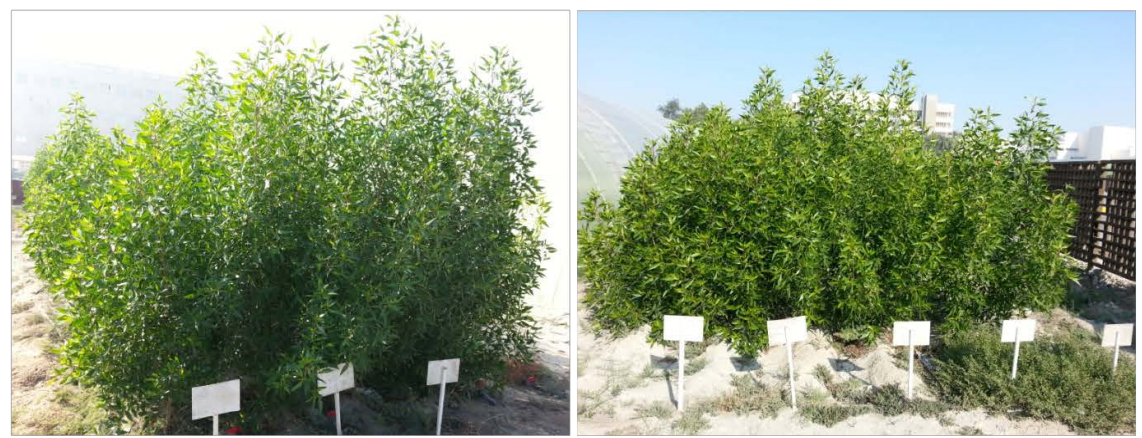

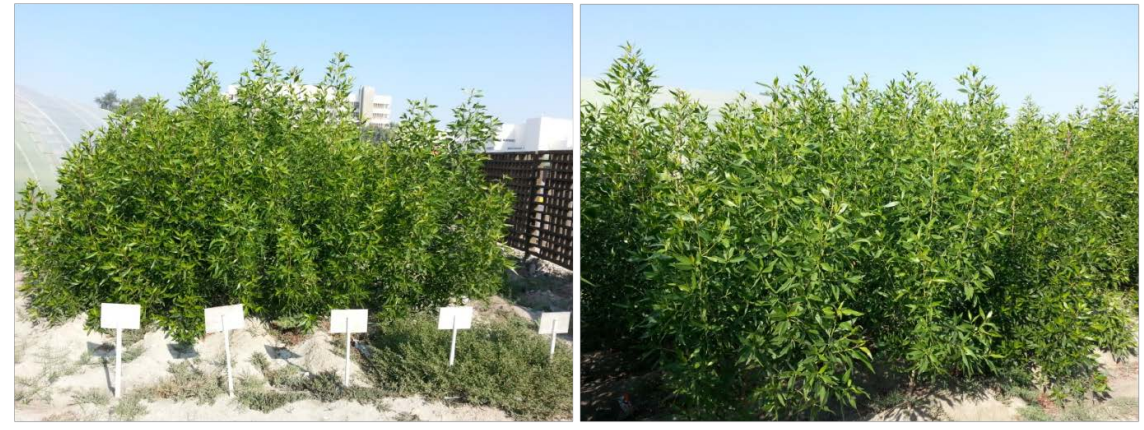

(April 1, 2015)
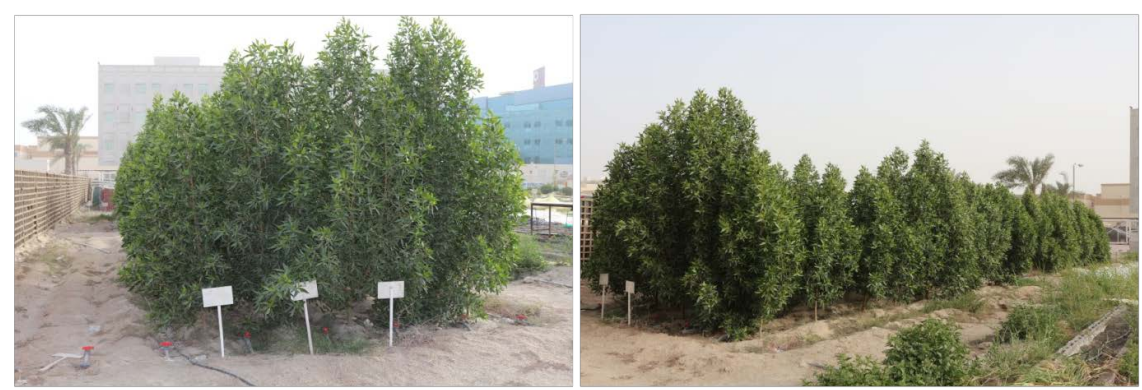

Figure 1. The growing stages of the Conocarpus erectus trees in the experimental pilot area at the Arabian Gulf University, Bahrain.

\subsection{Mashtul Pilot Area, Egypt}

The field work was carried out in the Mashtul Pilot Area (MPA). MPA was constructed in 1980 in south-eastern part of the Nile Delta [5]. It is situated $90 \mathrm{~km}$ northeast of Cairo in a rather flat area. The area is approximately 260 feddans. Table 1 shows Irrigation schedule \& amount and crop productivity in the Mashtul Pilot Area, 2005. The southern and western boundaries are formed by the Mahmoudia Drain and its branch; the northern and eastern are bound by tertiary irrigation canals. It is characterized by a deep clay top layer and a sandy aquifer. The clay layer, which is approximately $6.0 \mathrm{~m}$ thick, contains about $35 \%$ silt and $65 \%$ clay. Irrigation water is delivered by gravity to the tertiary canals and lifted approximately $0.5 \mathrm{~m}$ to field level by pumps.

The area is drained through a subsurface drainage system that consists of parallel PVC lateral drains, which discharge into buried concrete collector drains through a manhole. The design of the subsurface drainage system was made according to the standard criteria of the Egyptian Public Authority for Drainage Projects (EPADP). Two types of criteria can be distinguished; namely, the agricultural and the technical ones. The agricultural criteria are an average depth of the groundwater table midway between the drains of $1.0 \mathrm{~m}$ and an average drainage rate of $1.0 \mathrm{~mm} /$ day to permit sufficient leaching. The technical criteria are a design discharge rate for the determination of drain pipe capacity of $4 \mathrm{~mm} /$ day for rice areas and $3 \mathrm{~mm} /$ day for other crops, a safety factor of $25 \%$ in the design 
Table 1. Irrigation schedule \& amount and crop productivity in the Mashtul Pilot Area, 2005.

\begin{tabular}{ccccc}
\hline Crop & Irrigation schedule & $\begin{array}{c}\text { No. of } \\
\text { irrigations }\end{array}$ & $\begin{array}{c}\text { Irrigation } \\
\text { applied } \mathrm{m}^{3} / \text { feddan }\end{array}$ & $\begin{array}{c}\text { Crop productivity } \\
\text { kg/feddan }\end{array}$ \\
\hline Wheat & $\begin{array}{c}40-60 \text { days after first } \\
\text { irrigation then every 30 days }\end{array}$ & 3 & $1500-1900$ & 5088 \\
Maize & every 20 days & 6 & $2000-2700$ & 4233 \\
\hline
\end{tabular}

of the collector drains to account for sedimentation and misalignment and change in diameters and maximum depth of $1.5 \mathrm{~m}$ for laterals and $2.5 \mathrm{~m}$ for collectors. The area was divided into eighteen drainage units with different drain depths and spacing. The units were cultivated with a single crop for each unit during each cropping season. Berseem (Egyptian clover) and wheat were cultivated as winter crops and cotton, rice, and maize as summer crops [6].

\section{Method and Materials}

The SALTMED model [7] [8], which was designed to be, generic, physically based, friendly to use and to include a number of physical processes acting simultaneously under field conditions was evaluated in experimental work. The model under all irrigation systems incorporates: evapotranspiration, plant water uptake, water and solute transport and crop yield and biomass production based on a relationship between water uptake and biomass. The water balance model is formulated for unsaturated condition. This condition can be conceptualized as four boxes in which the water content fluctuates over time. The model traces the portion of the irrigation water evapotranspired and the portion infiltrated through each layer and finally recharges the groundwater. The dynamics of water table and groundwater intrusion to the root zone are also represented. The water flow in soils was described mathematically by the well-known Richard's equation. It is a partial non-linear differential equation, partial in time and space. It is based on two soil physical principles: Darcy's law and mass continuity. The vertical transient-state flow water in a stable and uniform segment of the root zone can be described by a Richard's type equation. The convection flux generally causes hydrodynamic dispersion too, an effect that depends on the microscopic non-uniformity of flow velocity in the various pores. Thus, a sharp boundary between two miscible solutions becomes increasingly diffuse about the mean position of the front. For such a case, the diffusion coefficient has been found by Bresler [9] to depend linearly on the average flow velocity. In the one dimensional PRD model used for basin irrigation, the calculation is carried out on three columns each of which has $1 \mathrm{~m}$ width and $2 \mathrm{~m}$ depth. The left and right columns are acting as boundary conditions to the middle column. The result of the middle column is the considered one. A detailed description of each functional relationship is given by Ragab et al. [10]. The STD treatment was used to calibrate the Saltmed model for wheat crop in winter season and maize crop in summer season, 2005. After the calibration, 
the model was used to examine and simulate the PRD technique in MPA for the same crops.

\section{Results and Discussion}

Applying irrigation management by using regulated deficit irrigation and subsequent trial have included simulating PRD was arranged in two experimental fields cultivated with wheat and maize. In the 2005 growing winter season for wheat and summer season for maize, PRD was modeled in MPA on a clay soil. The results confirmed an increase in apparent irrigation water use efficiency when compared with conventional flood irrigation. In this trial there were three irrigation cycles during the winter season and six cycles during the summer season, and water was carefully applied and modeled in two ways, as follows: Standard Flood Irrigation (STD) where the entire section was flooded and Partial Rootzone drying (PRD), where only one side of each crop line received water. The results indicated that the measured productivity of wheat and maize using STD was $5088 \mathrm{~kg} / \mathrm{fed}$ and $4233 \mathrm{~kg} / \mathrm{fed}$ in winter and summer season, $2005 \mathrm{re}-$ spectively. The STD measured data were used to calibrate the Saltmed model, after the calibration, the Saltmed model was used to simulate the crop yield and the water use efficiency of the PRD treatment.

The model performance evaluation was based on comparing measured with modeled crop yield and water use efficiency in MPA maintained under STD treatment using indexes that are calculated on the basis of the square of modeling errors, the coefficient of determination ( $\mathrm{R}^{2}$; [11] [12] [13] [14] [15]). The evaluation results indicated that there is a good agreement between the historical measured and the simulated data. The amount of the applied irrigation was $1750 \mathrm{~m}^{3}$ and $2350 \mathrm{~m}^{3}$ respectively (Table 2). The high yields have been traditionally achieved by using surface irrigation. Table 2 shows water input, crop yield and water use efficiency in MPA maintained under two different irrigation treatments; STD and PRD in 2005. After the calibration of the Saltmed model using the STD treatment, the model was used to simulate the PRD treatment. From Table 2 and expressing yield in terms of water productivity, the modeling results indicated that PRD is outstanding. PRD thus "worked" as a deficit irrigation treatment, sustaining a similar (even higher) yield compared with conventional flood irrigation (STD), not necessarily through a change in water-use efficiency itself but possibly by "forcing" crops to access more soil water than did crops on STD. The improvement in water use efficiency under the PRD treatment (Table 2) must also be viewed against this same background. The modeling results indicated that, the soil water content did increase and would have contributed to an improvement in irrigation water use efficiency. The dynamic changes in rootzone water content did not extend any deeper than about $80 \mathrm{~cm}$. The measured and simulated crop yield in MPA trial maintained under STD and PRD irrigation treatments in 2005 are shown in Figure 2 while, Figure 3 shows the water use efficiency. 
Table 2. Water input, crop yield and water use efficiency (MPA trial) maintained under two different irrigation treatments; STD and PRD in 2005.

\begin{tabular}{ccccccccc}
\hline & \multirow{2}{*}{$\begin{array}{c}\text { Irrigation } \\
\text { applied } \\
\left(\mathrm{m}^{3} / \mathrm{fed}\right)\end{array}$} & \multicolumn{3}{c}{ Yield $(\mathrm{kg} / \mathrm{fed})$} & \multicolumn{2}{c}{$\begin{array}{c}\text { Yield/Irrigation applied } \\
\left(\mathrm{kg} / \mathrm{m}^{3}\right)\end{array}$} \\
\cline { 4 - 10 } & & Measured & Simulated & Measured & \multicolumn{2}{c}{ Simulated } \\
\hline Crop & STD & PRD & STD & STD & PRD & STD & STD & PRD \\
Wheat & 1750 & 1200 & 5088 & 5104 & 3780 & 2.91 & 2.92 & 3.15 \\
Maize & 2350 & 1650 & 4233 & 4319 & 3402 & 1.80 & 1.83 & 2.06 \\
\hline
\end{tabular}

$\mathrm{STD}=$ standard flood irrigation; $\mathrm{PRD}=$ partial rootzone drying.

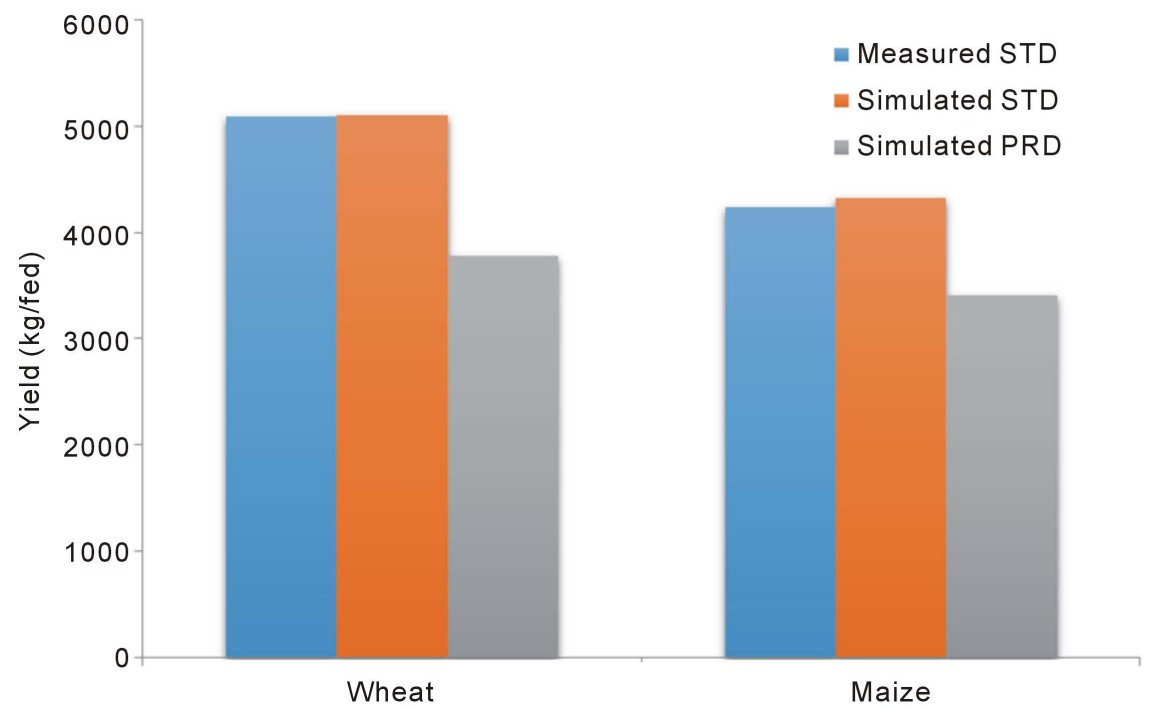

Figure 2. Measured and simulated crop yield in MPA trial maintained under STD and PRD irrigation treatments in 2005.

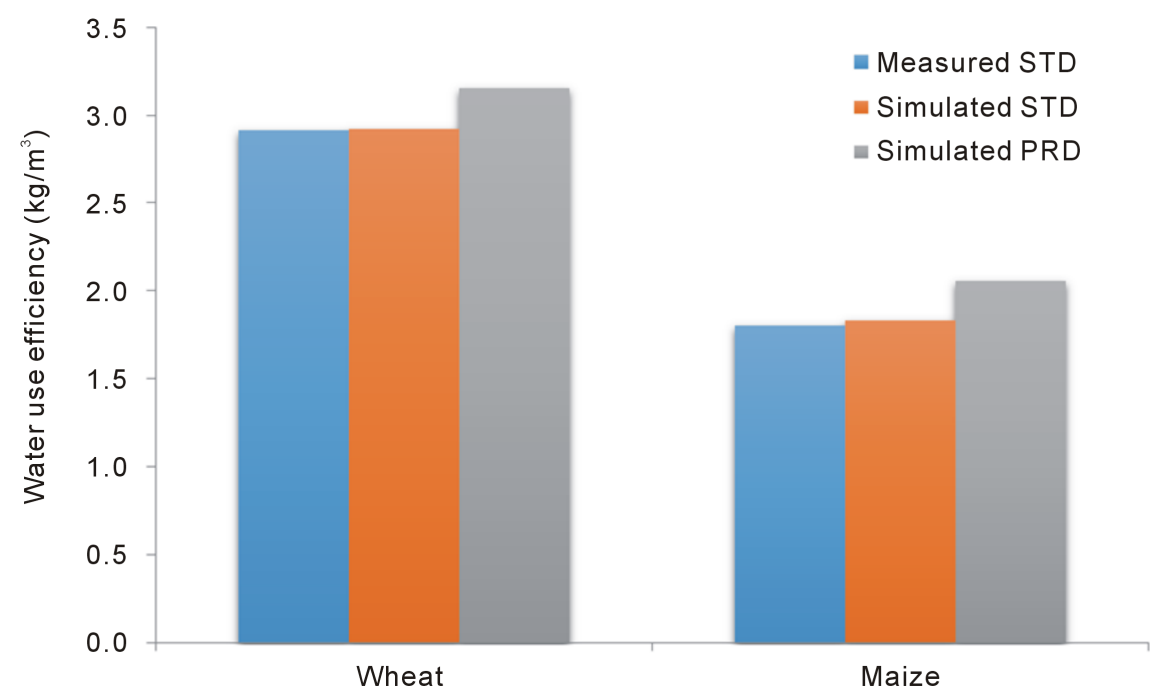

Figure 3. Measured and simulated water use efficiency in MPA trial maintained under STD and PRD irrigation treatments in 2005. 
PRD irrigation method requires that both wet and dry rootzones are both simultaneously created. PRD method is a sensitive technique need very precise irrigation scheduling and good distribution uniformity is required to implement these techniques. The experiments have also shown that the dry roots are maintained in a healthy condition by water supplied to them from the wet roots [16] [17] [18] [19]. This technique is capable of producing very high water use efficiency and improving crop quality for certain varieties. The PRD method will affect on water use efficiency, plant quality and nitrate leaching within the soil profile. PRD technique increases water use efficiency through a stress related chemical produced by the drying roots which is then transported to the leaves. The chemical brings about physiological changes that reduce water lost from leaves through evapotranspiration. In addition to water saving, PRD has also been showed to have beneficial effects on the nutrient uptake of wheat and maize crops compared with STD. The modeling results of this research are summarized below:

- Compared to fully irrigated crops, leaf evapotranspiration was reduced.

- The effect of PRD on trunk growth was significant on both crops.

- Physiological changes associated with the release of the stress related chemical were observed.

- The PRD treatment reduced water application rates by $32 \%$ and $30 \%$ for wheat and maize respectively.

Compared to flood irrigation, PRD treatment increased water productivity by $7 \%$ and $12 \%$ respectively and showed a reduction in crop yield by $27 \%$ and $18 \%$ respectively.

\section{Conclusion}

As PRD irrigation is in the research phase, further experiences are needed to evaluate economical advantages of PRD irrigation. PRD was very useful and significant step forward in improving the water productivity of some Conocarpus erectus trees. While there were some risks of water stress to some trees, with careful soil water monitoring these risks was minimized. Satisfactory implementation of deficit water strategies in warm seasons (periods with high levels of water evaporation) required responsive watering systems and soils with high infiltration rates. The results showed that more experimental research areas should be designed to the practical application and longer term consequences of the proposed irrigation method. Food security requires production of more crops per water drop. The results showed that, saving in water is significant $(\sim 30 \%)$ which means $30 \%$ food more can be produced. It is recommended to apply the PRD irrigation method in many experimental areas with different soil types and crops to validate the method. In terms of economic positional impact, the research (with efficient irrigation systems) highly recommended applying the PRD method in the GCC countries to save water and improve crop quality. Further research is needed to gain a better understanding of how this technique affects 
the distribution of soil moisture within the root zone and the development and physiology of crop growing phases on a range of soil textures and depths. Finally, the research highly recommends applying the PRD method in the GCC countries and in new reclaimed areas in Egypt such as million and 500 thousands faddens to save water and improve crop quality.

\section{Acknowledgements}

The authors would like to thank Arabian Gulf University for financing this research project via the Internal Research Grant Number DAZ04. They would also like to thank the anonymous reviewers for their constructive rectifications and comments.

\section{References}

[1] Kang, S.Z., Li, Z.J., Hu, X.T., Jerie, P. and Zhang, L. (2001) An Improved Water Use Efficiency for Hot Pepper Grown under Controlled Alternate Drip Irrigation on Partial Roots. Scientia Horticulturae, 89, 257-267. https://doi.org/10.1016/S0304-4238(00)00245-4

[2] Kang, S., Hu, X., Goodwin, I. and Jerie, P. (2002) Soil Water Distribution, Water Use, and Yield Response to Partial Root Zone Drying under Shallow Groundwater Table Condition in a Pear Orchard. Scientia Horticulturae, 92, 277-291. https://doi.org/10.1016/S0304-4238(01)00300-4

[3] Kang, S.Z., Shi, W.J., Cao, H.X. and Zhang, J. (2002) Alternate Watering in Soil Vertical Profile Improved Water Use Efficiency of Maize (Zea mays). Field Crops Research, 77, 31-41. https://doi.org/10.1016/S0378-4290(02)00047-3

[4] Kang, S.Z. and Zhang, J. (2004) Controlled Alternate Partial Root-Zone Irrigation: Its Physiological Consequences and Impact on Water Use Efficiency. Journal of EXperimental Botany, 55, 2437-2446. https://doi.org/10.1093/jxb/erh249

[5] Drainage Research Institute (DRI) (1987) Mashtul Pilot Area, Physical Description. Technical Report No. 57, Pilot Areas and Drainage Technology Project, Drainage Research Institute, Cairo, Egypt.

[6] El-Sadek, A., Sallam, G. and Embaby, M. (2013) Using DRAINMOD-Geostatistical Technology to Predict Nitrate Leaching: A Case Study of Mashtul Pilot Area, Egypt. Irrigation and Drainage Engineering, 139, 158-164. https://doi.org/10.1061/(ASCE)IR.1943-4774.0000491

[7] Ragab, R. (2002) A Holistic Approach for Irrigation, Crop and Field Management: The Saltmed Model. Environmental Modelling \& Software, 17, 345-361. https://doi.org/10.1016/S1364-8152(01)00079-2

[8] Ragab, R. (2002) An Integrated Modelling Approach for Irrigation Water Management Using Saline and Non-Saline Water. The Saltmed Model. Acta Hort., 573, 129-138. https://doi.org/10.17660/ActaHortic.2002.573.15

[9] Bresler, E. (1975) Two-Dimensional Transport of Solute during Non-Steady Infiltration for a Trickle Source. Soil Science Society of America Journal, 39, 604-613. https://doi.org/10.2136/sssaj1975.03615995003900040014x

[10] Ragab, R., Malash, N., Abdel Gawad, G., Arslan, A. and Ghaibeh, A. (2005) A Holistic Generic Integrated Approach for Irrigation, Crop and Field Management: 1. The SALTMED Model and Its Calibration Using Field Data from Egypt and Syria. Agricultural Water Management, 78, 67-88. 
https://doi.org/10.1016/j.agwat.2005.04.022

[11] Legates, D.R. and McCabe, G.J. (1999) Evaluating the Use of "Goodness-of-Fit" Measures in Hydrologic and Hydroclimatic Model Validation. Water Resources Research, 35, 233-241. https://doi.org/10.1029/1998WR900018

[12] Tang, L.S., Li, Y. and Zhang, J. (2005) Physiological and Yield Responses of Cotton under Partial Rootzone Irrigation. Field Crops Research, 94, 214-223. https://doi.org/10.1016/j.fcr.2005.01.005

[13] El-Sadek, A. (2014) Stochastic Approach to Assess a Nitrate Process-Factor in Soil Water. Ain Shams Engineering Journal, 5, 315-320. https://doi.org/10.1016/j.asej.2013.10.006

[14] Saleh, W., Hujair, T. and El-Sadek, A. (2013) Environmental Mechanism for Assessing Point Sources Pollution in Wadi Gaza, Palestine. Arab Gulf Journal of Scientific Research, 29, 51-58.

[15] El-Sadek, A., Feyen, J. and Berlamont, J. (2001) Comparison of Models for Computing Drainage Discharge. Irrigation and Drainage Engineering, 127, 363-369. https://doi.org/10.1061/(ASCE)0733-9437(2001)127:6(363)

[16] El-Sadek, A. (2002) Modeling of $\mathrm{NO}_{3}-\mathrm{N}$ Leaching to Shallow Groundwater during the Fall-Winter Season. The Scientific World Journal, 2, 1006-1016. https://doi.org/10.1100/tsw.2002.204

[17] El-Sadek, A., Feyen, J., Skaggs, W. and Berlamont, J. (2002) Economics of Nitrate Losses from Drained Agricultural Land. Environmental Engineering, 128, 376-383. https://doi.org/10.1061/(ASCE)0733-9372(2002)128:4(376)

[18] El-Sadek, A., Feyen, J. and Ragab, R. (2002) Simulation of Nitrogen Balance of Maize Field under Different Drainage Strategies Using the DRAINMOD-N Model. Irrigation and Drainage, 51, 61-75. https://doi.org/10.1002/ird.33

[19] El-Sadek, A., Radwan, M. and Feyen, J. (2001) Numerical Analysis of the Transport and Fate of Nitrate in the Soil and Nitrate Leaching to Drains. The Scientific World Journal, 1, 170-180. https://doi.org/10.1100/tsw.2001.344 